\title{
Contribuição ao estudo da conectividade entre os Sistemas Aquíferos Serra Geral (SASG) e Guarani (SAG) no Estado do Paraná, Brasil.
}

Contribution to the study of connectivity between the Serra Geral Aquifer System (SASG) and Guarani Aquifer System (SAG) in the State of Paraná, Brazil

GUSTAVO BARBOSA ATHAYDE ${ }^{1}$, CAMILA MÜLLER ATHAYDE², ERNANI FRANCISCO ROSA FILHO², OTAVIO AUGUSTO BONI LICHT ${ }^{3}$

1Universidade Federal de Pelotas - UFPEL, RS - gustavo_athayde@yahoo.com.br

2Universidade Federal do Paraná - UFPR, PR - camilavmuller@yahoo.com.br, ernani@ufpr.br

${ }^{3}$ Mineropar-PR - otavio@mineropar.pr.gov.br

\begin{abstract}
Resumo
O Sistema Aquífero Serra Geral (SASG) é um dos aquíferos mais importantes para o Estado do Paraná, principalmente em função da excelente qualidade química e potencialidade de produção (poços com vazões e capacidades específicas elevadas). Subjacente ao SASG, o Sistema Aquífero Guarani (SAG) está confinado por espessuras de até 1437 metros de rochas basálticas no estado do Paraná (Cianorte/PR). Em muitos casos, existe jorrância em poços que captam o SAG no território paranaense, com águas enriquecidas em elementos dissolvidos, principalmente na área de confinamento, tornando-as impróprias para o consumo humano e irrigação. A partir da análise físico-química de poços que seccionam o SASG, foram observadas amostras com características químicas muito semelhantes às águas do SAG. Nos locais onde existe a mistura de águas entre os dois aquíferos, as águas do SASG podem ser "contaminadas" e assim, restringir a sua aptidão para consumo humano in natura. Este trabalho apresenta a localização de poços (ou agrupamento desses) que apresentam indícios físico-químicos e relações potenciométricas, favoráveis à mistura de águas entre o SASG e SAG no Estado do Paraná.
\end{abstract}

Palavras-chave: Sistema Aquífero Serra Geral, Sistema Aquífero Guarani; mistura de águas; Estado do Paraná.

\begin{abstract}
The Serra Geral Aquifer System (SASG) is one of the most important aquifers in the Paraná State, mainly due to the excellent chemical quality and potential production (wells with high flows and specific capacities). Below the SASG, the Guarani Aquifer System (SAG) is confined by 1437 meters of basalt in the Paraná State (Cianorte / PR). In many cases in the State of Paraná, water wells that capture groundwater from SAG are enriched in dissolved elements, especially in the confinement area, with restrictive hidrochemical characteristics for human consumption. Some physicochemical analyzes from wells that pump SASG shows similar chemical characteristics with the SAG groundwater. The mixing of two aquifers can be ascertained by water from SASG possibly contaminated, providing water with restrictions for in natura human consumption. The physicochemical characteristics and favorable potentiometric relationships may provide the location of wells (or groups of wells) that exhibit evidencesof mixing groundwater between SASG and SAG in the Paraná State.
\end{abstract}

Keywords: Serra Geral Aquifer System; Guarani Aquifer System; mixing water; Paraná State.

\section{INTRODUÇÃO}

As águas do SASG são classificadas predominantemente como bicarbonatas cálcicas, enquanto nas águas do SAG, em suas porções de alto confinamento, predominam os ânions sódio, sulfato e cloreto. Ao identificar águas no SASG com características diferentes do padrão químico bicarbonatada cálcica, concomitante com temperatura e concentrações elevadas de ânions, levanta-se a hipótese de mistura de águas entre oSAG e SASG.

Inúmeros casos de jorrância em poços que captam o SAG, em áreas onde o litotipo aflorante é a Fm. Serra Geral são relatados em território paranaense. Estes casos demonstram que existe a possibilidade física de mistura de águas entre o SASG e o SAG em função das diferentes cargas hidráulicas.

Rosa Filho et al. (1987) consideram alguns tipos químicos de águas captadas em rochas basálticas do SASG, como resultantes da mistura de águas oriundas do SAG, hipótese também apontada por Bittencourt (1996), que trata, especificamente, dos controles geoquímicos das águas termais no Paraná. Trabalhos realizados por Buchmann Filho (2002), Souza (2004) e Hindi (2007), relatam a ascensão, através de zonas de fraturas, de águas do SAG até o SASG.

A integração dos dados físico-químicos e potenciométricos de poços distribuídos em ambos os 
sistemas aquíferos, SASG e SAG, foi realizada com objetivo de identificar áreas no SASG onde predominam poços com características físico-químicas diferentes do quimismo predominante das águas.

Sabe-se que, a mistura de águas apenas é possível quando existem relações potenciométricas favoráveis, ou seja, quando a superfície potenciométrica do SAG está em cota superior à superfície potenciométrica do SASG. Nestes casos, pressupõe-se que a mistura de águas esteja condicionada pela ocorrência de estruturas tectônicas que possibilitem a conectividade estrutural entre os aquíferos.

\section{MATERIAIS E MÉTODOS}

A rotina de análise utilizada nesta pesquisa, para identificar zonas de agrupamento de poços tubulares que, possivelmente apresentam mistura de águas, a misturas de águas entre o SASG e o SAG pode ser assim resumida:

- Caracterização dos principais tipos de água em ambos os aquíferos: as análises físico-químicas dos poços que captam o SASG foram as utilizadas por Athayde (2013). As análises de água dos poços que captam o SAG foram obtidas em Hindi (2007);

- Traçado da cota potenciométrica do SAG selecionada, neste caso 400 m.s.n.m;

- Mediante técnicas de geoprocessamento, foram selecionados poços do SASG, que apresentaram características hidroquímicas (análises físicoquímicas) e potenciométricas (cota do nível estático), favoráveis à mistura de águas (ascensão doSAG);

- Delimitação de zonas de agrupamento de poços onde foram identificadas uma elevada probabilidade de mistura de águas entre os aquíferos.

\subsection{Poços que captam o Sistema Aquífero Serra Geral - SASG}

Nesta pesquisa foram utilizados 337 poços tubulares profundos pertencentes à Companhia de Saneamento do Paraná - SANEPAR, Prefeitura de Marechal Cândido Rondon, Prefeitura de Pato Bragado e Prefeitura de Entre Rios do Oeste (Figura 1).

Nos 337 poços tubulares foram realizadas amostragens de água para determinação dos principais cátions e ânions, assim como foram determinados em campo os parâmetros: $\mathrm{pH}$; temperatura e condutividade elétrica $(\mu \mathrm{S} / \mathrm{cm})$. A campanha de amostragem dos 337 poços ocorreu entre os anos de 2007 e 2009 (Athayde et al., 2012).

Dados de localização (coordenadas UTM, SAD 1969, 22S) e profundidade do nível estático foram obtidos junto à ficha construtiva dos poços tubulares profundos. Ato contínuo, os resultados foram tabelados em planilha eletrônica, compondo o banco de dados deste estudo.

As medidas de profundidade do nível estático foram obtidas em diferentes datas, mensuradas nos respectivos períodos de perfuração dos poços. Para obtenção de uma medida mais exata, seria necessário paralisar o bombeamento em todos os poços, aguardar a recuperação e estabilização do nível estático, contudo este procedimento é inexequível, uma vez que todos os poços aqui analisados são utilizados para abastecimento público.

Do total de 337 amostras de água analisadas em poços que captam o SASG, predominaram águas do tipo bicarbonatada cálcica (198 amostras), secundariamente águas bicarbonatadas sódicas (50 amostras), seguidas por águas bicarbonatadas cálcio-magnesianas (25 amostras), carbonatadas sódicas (23 amostras), bicarbonatada cálcio-sódica (19 amostras), bicarbonatadas sódio-cálcicas (13 amostras). Em menor quantidade ocorrem os seguintes tipos hidroquímicos: bicarbonatada sulfatada-sódica, bicarbonatadacarbonatada sódica, sulfatada sódica, bicarbonatada magnésio-cálcica, bicarbonatada nitrato-sódica e nitratada cálcio-sódica. Estas duas últimas com nítida influência antrópica em função dos elevados teores de nitrato nas águas.

Os limites geográficos da Formação Serra Geral aqui utilizados, foram extraídos do Mapa Geológico do Estado do Paraná (Mineropar, 2006). Para fins de representação gráfica a Formação Serra Geral está apresentada em tons de cinza. O arcabouço estrutural traçado é o proposto por Athayde et al., (2012). 


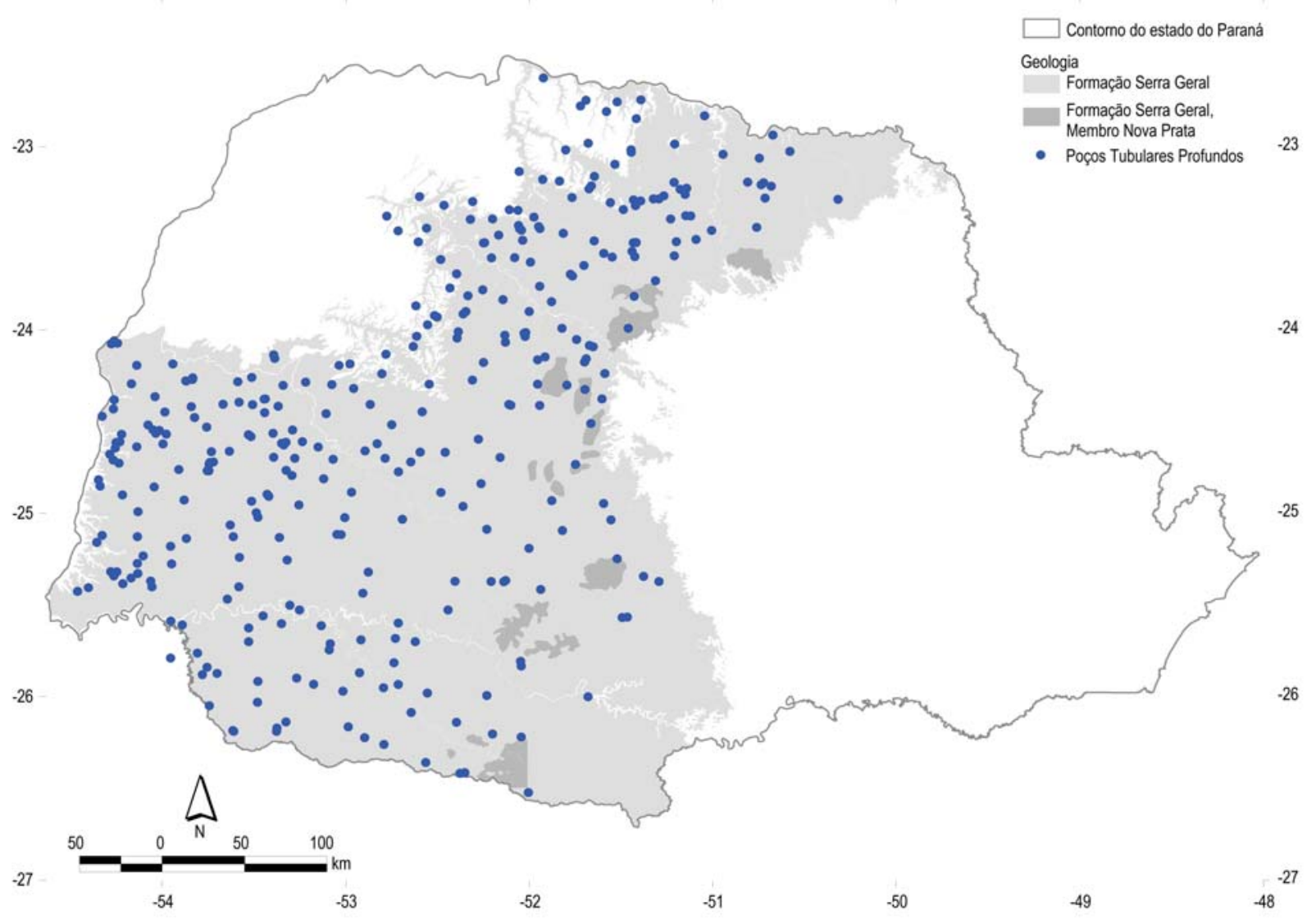

Figura 1 - Localização dos poços tubulares profundos (SASG) utilizados nesta pesquisa e distribuição das unidades geológicas da Formação Serra Geral no Estado do Paraná.

\subsection{Poços que captam o Sistema Aquífero Guarani - SAG}

O Sistema Aquífero Guarani (SAG), formado pelos arenitos das Formações Pirambóia e Botucatu ocorre, no Estado do Paraná, coberto pelos derrames de lava da Formação Serra Geral. Subjacentes aos arenitos ocorrem rochas sílticas e argilosas da Formação Rio do Rasto.

Para caracterizar os tipos químicos do SAG foram utilizadas as análises físico-químicas de 65 poços que captam o SAG, utilizadas por Hindi (2007).

Em zona aflorante e baixo confinamento, $\mathrm{o}$ referido autor determina a existência de água do tipo bicarbonatada cálcica, bicarbonatada sódica e bicarbonatada cálcica-magnesiana. Na zona de médio confinamento definida por Hindi (2007), as análises indicam água do tipo bicarbonatada sódica, bicarbonatada cálcica, bicarbonatada sódica, bicarbonatada-sulfatada sódica e sulfatada sódica, enquanto que na zona de alto confinamento ocorrem águas do tipo bicarbonatada sódica, sulfatada sódica e cloretada-sulfatada sódica.

A temperatura da água medida na superfície do terreno varia de 20 a $65{ }^{\circ} \mathrm{C}$ e, as geotemperaturas máximas calculadas com as equações de geotermômetros variaram de 72 a $103^{\circ} \mathrm{C}$ (Hindi, 2007).

\subsection{Relações potenciométricas regionais}

A relação potenciométrica entre os aquíferos foi definida pela comparação entre a cota do nível estático nos poços do SASG e a cota potenciométrica 400 m.s.n.m. do SAG paranaense, tal como proposto por Hindi (2007).

Quando o nível estático do SASG situa-se em cotas inferiores a superfície potenciométrica do SAG existe a possibilidade física (relação de pressão entre os aquíferos) de conectividade / mistura de águas entre esses sistemas aquíferos. Ressalta-se a necessidade de estruturas tectônicas ou descontinuidades estratigráficas que permitam a conectividade entre os sistemas aquíferos. Destaca-se a existência de jorrância em poços do SAG em porções confinadas do aquífero, recobertas pela Formação Serra Geral.

Hindi (2007) descreveu nascentes termais na bacia hidrográfica do rio Iguaçu com quimismo semelhante ao SAG (situado a 800 metros de profundidade). A profundidade do nível estático e a localização dos poços que captam o SAG no Estado do 
Paraná, apresentados em Hindi (2007) pode ser observada no mapa da Figura 2.

Na região oeste do Paraná, próximo ao reservatório da Itaipu, Athayde et al. (2007) sugerem a mistura de águas entre o SASG e o SAG, através da observação das relações potenciométricas e similaridades químicas entre as águas captadas nos poços de ambos aquíferos. A (Figura 3) ilustra esquematicamente as relações potenciométricas de ambos aquíferos.

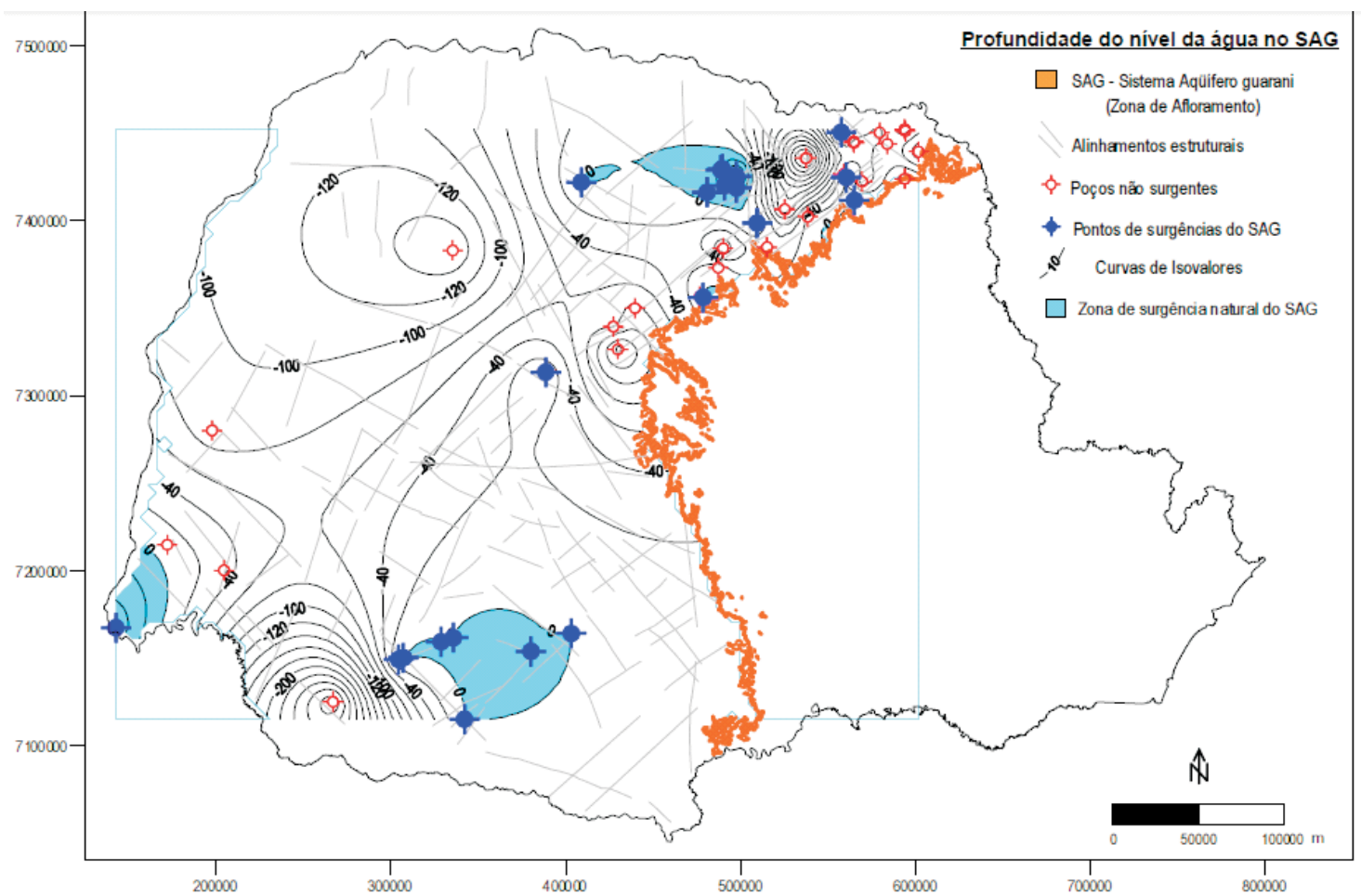

Figura 2 - Curvas de isoprofundidades da água no SAG, mostrando as zonas e pontos de surgência natural de água (isovalores em metro). Fonte: Hindi (2007).

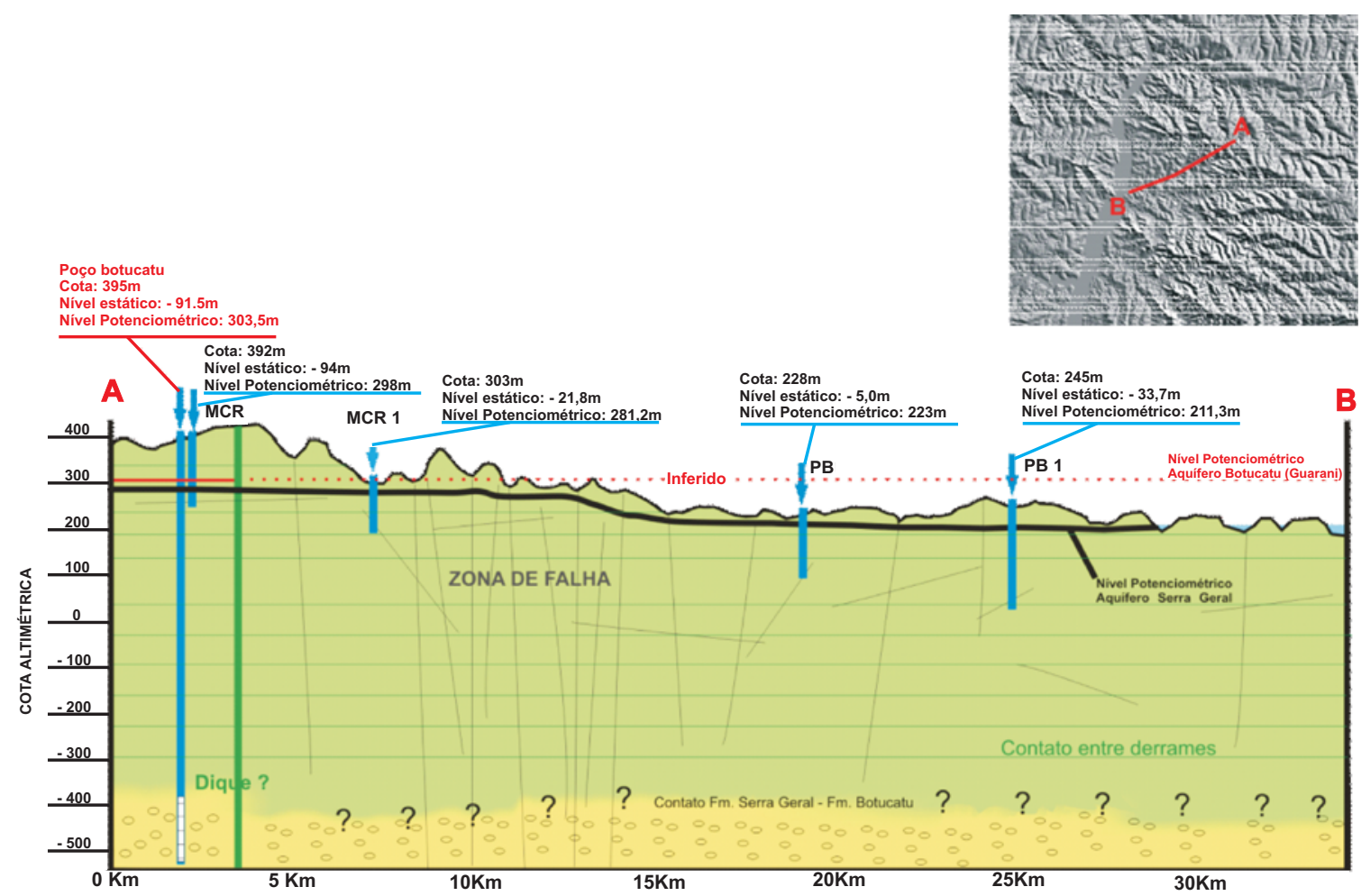

Figura 3 - Perfil hidrogeológico esquemático na bacia hidrográfica do Paraná III, ilustrando a possibilidade de mistura de águas entre o SASG e o SAG no oeste paranaense. Fonte: Athayde et al. (2007). 


\section{RESULTADOS}

\subsection{Relações potenciométricas entre o SASG e o SAG}

Para verificar as relações potenciométricas entre os dois aquíferos foram elaborados perfis regionais esquemáticos. A Figura 4 destaca a localização dos três perfis elaborados, ilustrados nas figuras 05, 06 e 07.

O perfil apresentado na figura 5 foi elaborado com dados dos poços tubulares que captam o SAG nos municípios de Faxinal, Novo Itacolomi, Jandaia do Sul, Maringá e Santa Fé, obtidos em Hindi (2007). Destacamse as diferentes profundidades do topo do
SAG, sugerindo a ocorrência de falhas com rejeitos da ordem de 964 metros entre poços distantes 110 quilômetros.

Esta geometria também permite a mistura de águas por contato lateral entre o SASG e SAG, fato que pode explicar a jorrância existente na região do município de Maringá e limítrofes. Os poços de Jandaia do Sul e Novo Itacolomi exemplificam o reflexo da compartimentação estrutural do SAG. Eles indicam as diferenças de profundidades do topo do SAG (477 metros) e do nível estático, em distâncias inferiores a 20 quilômetros.

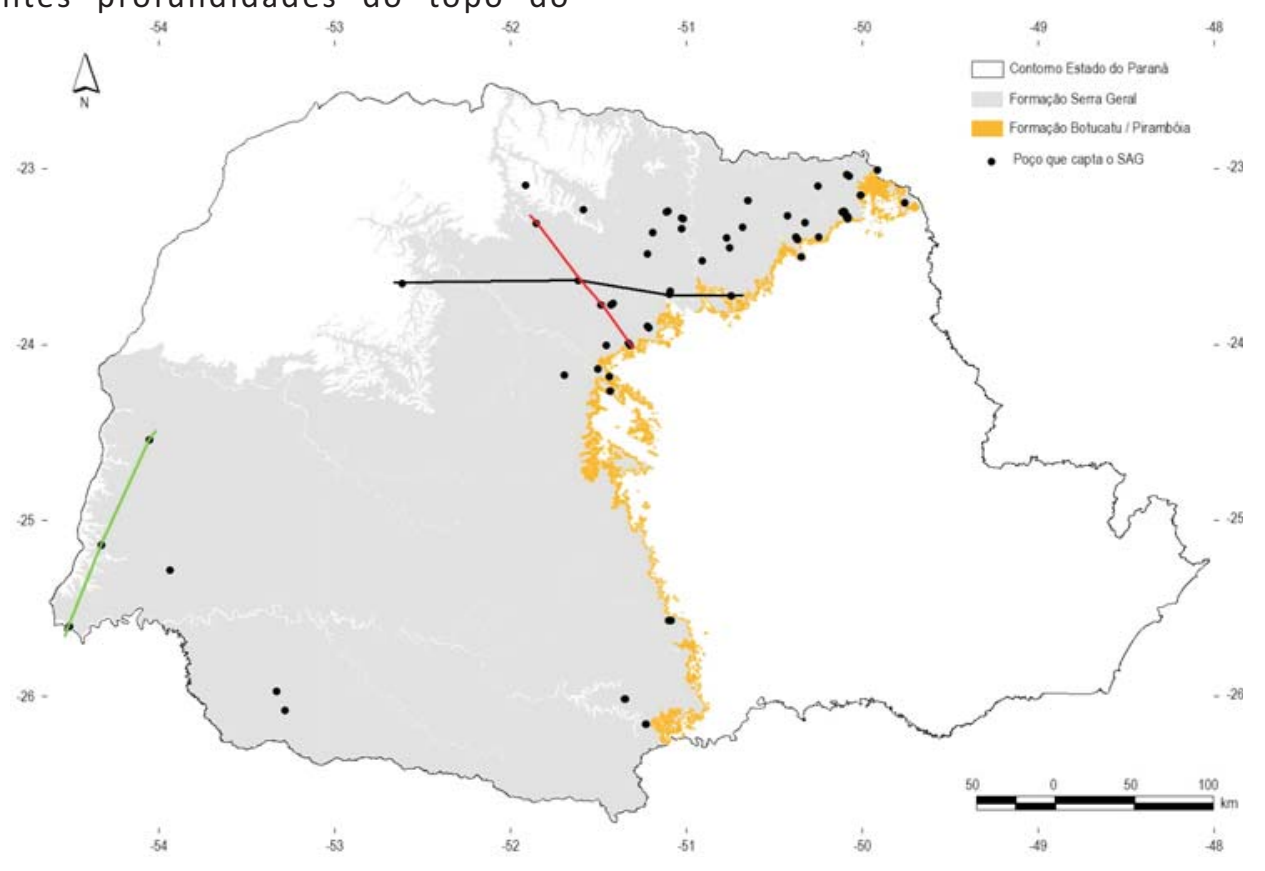

Figura 4-Localização dos perfis hidrogeológicos esquemáticos.

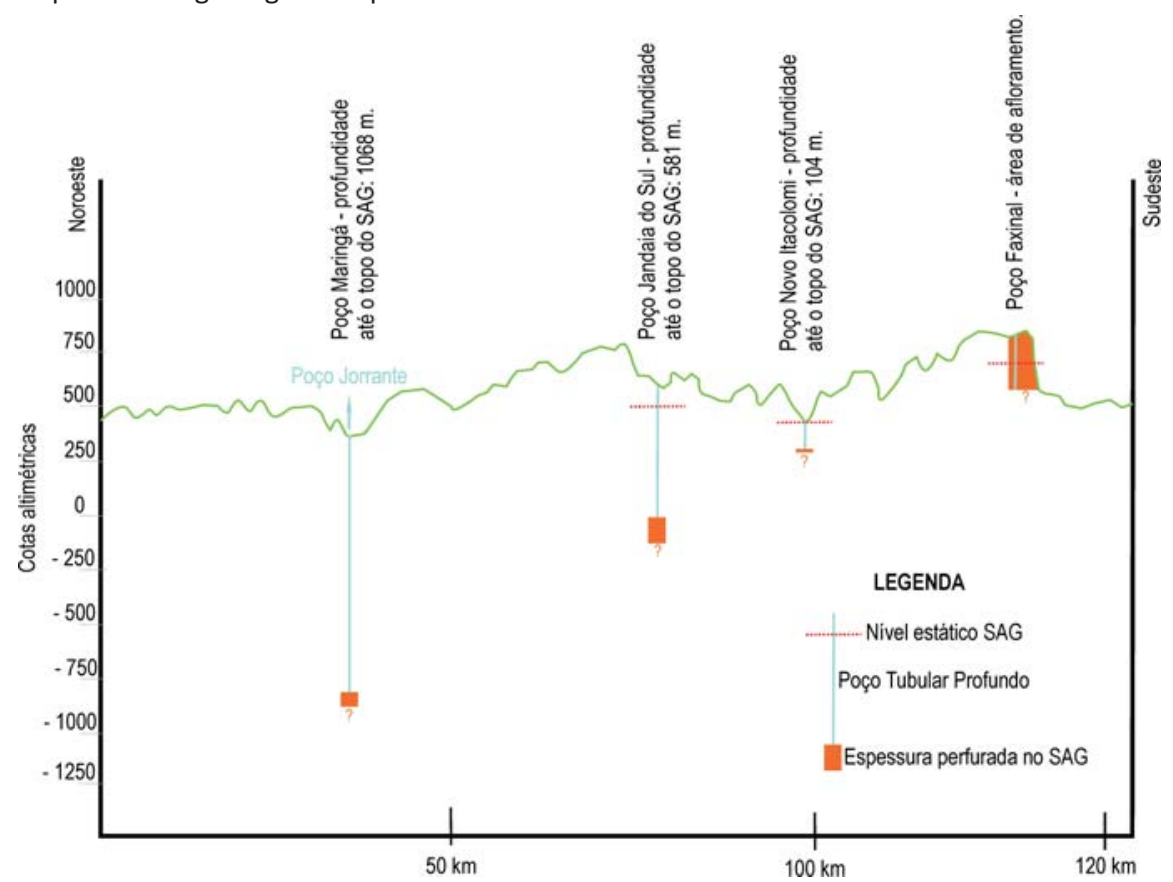

Figura 5 - Perfil hidrogeológico esquemático para poços locados nos municípios de Faxinal, Novo Itacolomi, Jandaia do Sul, Maringá e Santa Fé. Este perfil é representado por traço vermelho na Figura 4. 
Considerando as profundidades dos contatos entre a Formação Serra Geral (SASG) e a Formação Botucatu (SAG), apresentadas no perfil (Figura 6) com direção leste - oeste (linha preta na Figura 4) observa-se que o rio Ivaí está localizado em uma zona de falha geológica, a qual apresenta rejeitos de até 900 metros, em distâncias inferiores a 100 quilômetros. Isso pode ser observado considerando as diferentes cotas do topo do SAG (poços: Cianorte e Jandaia do Sul). Nesta mesma região (rio Ivaí), a cota do nível estático do SAG está também acima da superfície do terreno (possibilidade de poços jorrantes).

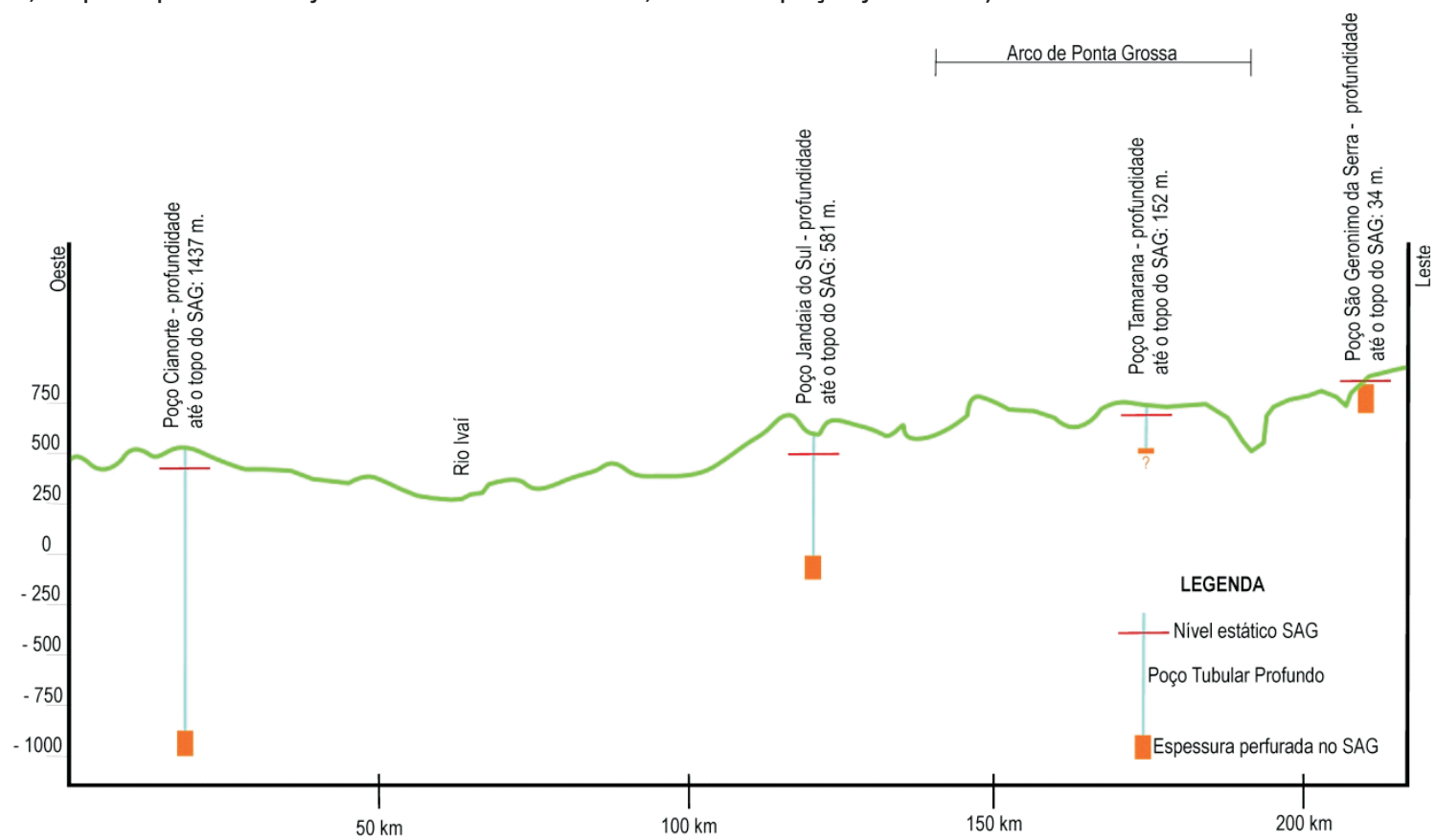

Figura 6 - Perfil hidrogeológico esquemático para poços locados nos municípios de Cianorte e Jandaia do Sul. Este perfil é representado por traço preto na Figura 4.

O perfil apresentado na Figura 7 está localizado na região oeste do Estado do Paraná (linha verde na Figura 4), com direção norte - sul, abrange poços situados nos municípios de Marechal Cândido Rondon, Itaipulândia e Foz do Iguaçu. Destaca-se a ocorrência de jorrância no poço tubular de Foz do Iguaçu, aproveitado para fins de turismo termal.
As relações potenciométricas entre o SASG e SAG na região oeste paranaense caracterizam a possibilidade de mistura de águas, principalmente em cotas inferiores a 300 m.s.n.m, corroborando a sugestão de Athayde et al., (2007) para mistura de águas entre os aquíferos na região do município de Marechal Cândido Rondon-PR.

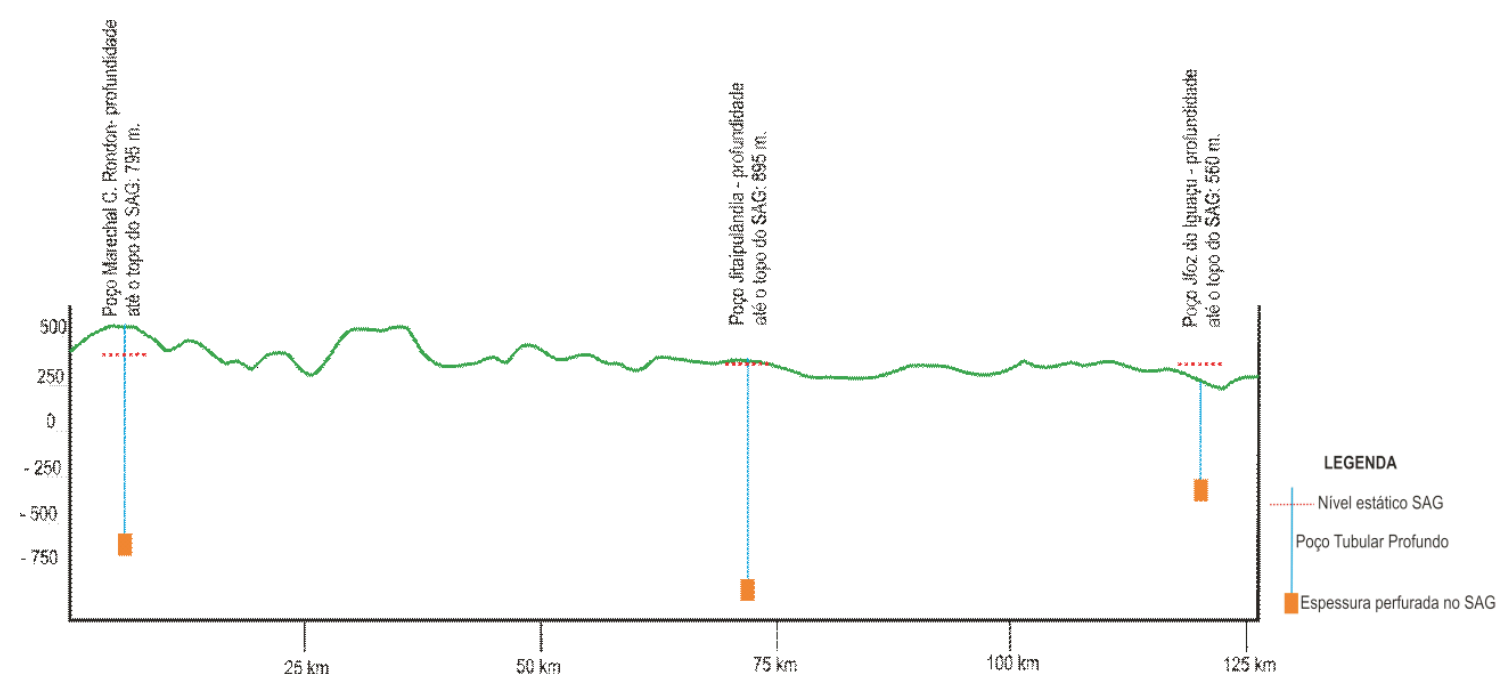

Figura 7 - Perfil hidrogeológico esquemático para poços locados nos municípios de Marechal Cândico Rondon, Itaipulândia e Foz do Iguaçu. Este perfil é representado por traço verde na Figura 4. 


\subsection{Localização e quimismo dos poços com possibilidade física de mistura de águas}

Considerando todos os 337 poços que captam o SASG, o valor da mediana da cota do nível estático é 450 metros sobre o nível do mar (m.s.n.m.).

Para fins de correlação potenciométrica entre os aquíferos considerou-se, nesta pesquisa, a cota potenciométrica do SAG de 400 m.s.n.m. Tal valor baseou-se na isolinha da potenciometria do SAG traçada por Hindi (2007), mais próxima à mediana da cota do nível estático do SASG calculada.

Desta forma, foram identificados os poços do SASG com cotas do nível estático inferiores a 400 m.s.n.m, e assim selecionados aqueles com relação potenciométrica favorável a mistura de águas (nível do SAG acima do nível do SASG).

A Figura 8 apresenta os poços do SASG que possuem nível estático com cota inferior a 400 metros. Nesta figura é indicada em tracejado vermelho a projeção da altitude 400 m.s.n.m. do nível estático do SAG, proposto por Hindi (2007).

Na Figura 9 os poços do SASG selecionados a partir da análise anterior, foram classificados em dois tipos principais de água, destacando as bicarbonatadas cálcicas dos outros tipos classificados. Estes últimos, destacam-se por apresentarem enriquecimento de sódio, cloreto, sulfato, carbonato, alto $\mathrm{pH}$ e aumento da temperatura das águas, ao compará-los com a mediana de todos os poços analisados nesta pesquisa.

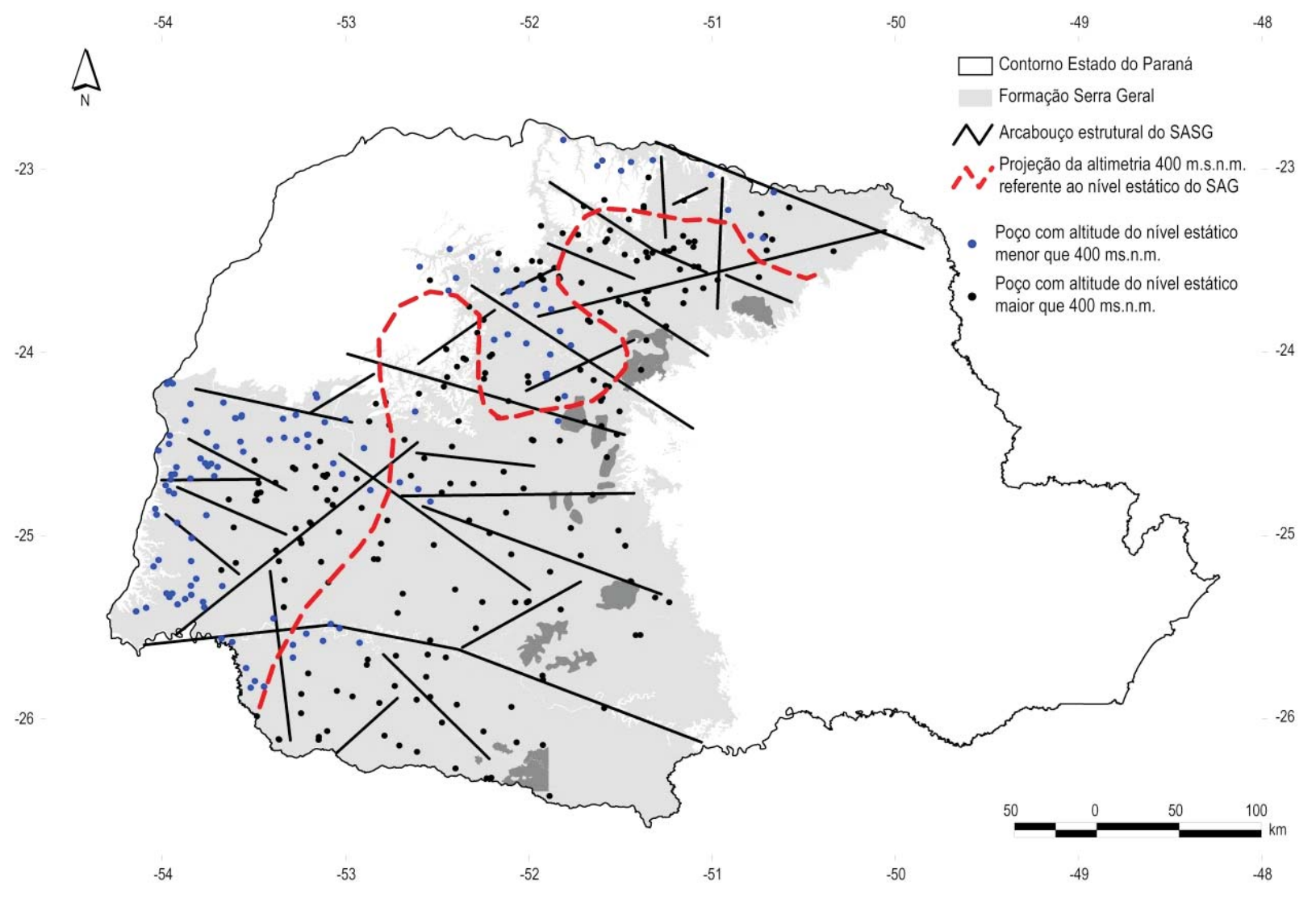

Figura 8 - Poços que captam o SASG e possuem nível estático inferior a 400 m.s.n.m.(poços em azul). Em vermelho, a isolinha da cota 400 metros do SAG proposta por Hindi (2007). 


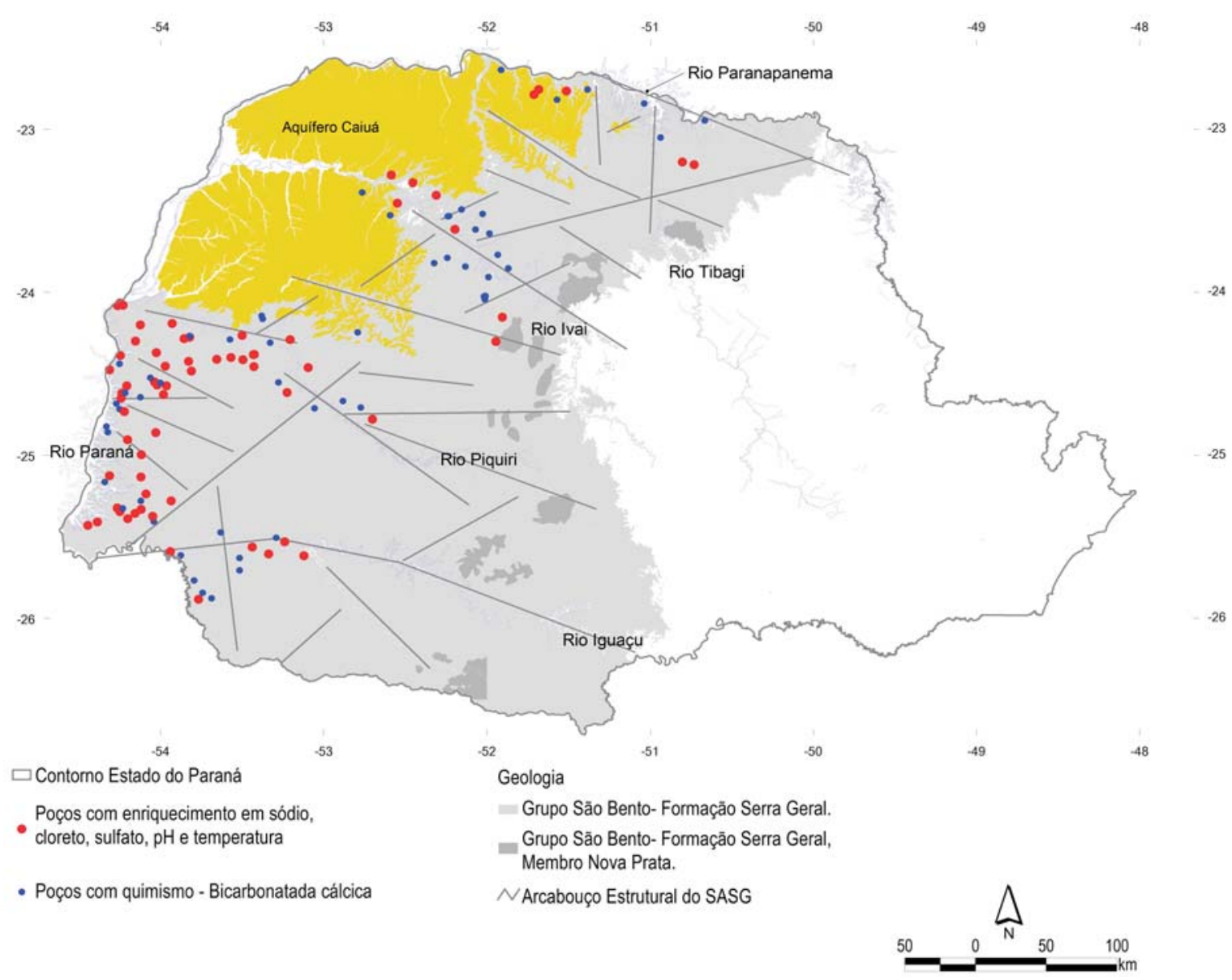

Figura 9-Mapa dos poços do SASG com potenciometria e quimismo que indicam a mistura de águas com o SAG.

\subsection{Caracterização das zonas regionais de mistura de águas}

Considerando que os poços com relações potenciométricas favoráveis à mistura de águas apresentam enriquecimento em sódio, cloreto, sulfato, carbonato, altos $\mathrm{pH}$ e temperatura, foi tentativamente criado um sistema de identificação de poços com indícios de conectividade entre oSASG e oSAG.

A mediana da temperatura dos poços com possibilidade física de conectividade é $23,4^{\circ} \mathrm{C}$, maior que a mediana de temperatura de todo o SASG $\left(22,6{ }^{\circ} \mathrm{C}\right)$. Considerando que no Estado do Paraná o SAG possui temperaturas de até $65^{\circ} \mathrm{C}$, e que o SASG é um aquífero classificado como frio (BRASIL, 1945); quando ocorre a mistura de águas entre os aquíferos SAG e SASG, eleva-se a temperatura das águas do SASG. Isso permite utilizar a temperatura como traçador natural, e de baixo custo.

A Figura 10 apresenta o mapa com a localização de todos os 337 poços doSASG analisados, com destaque para os poços (em vermelho) com características químicas e possibilidade física / hidráulica de mistura de águas SASG / SAG.

Analisando a distribuição desses poços, as áreas localizadas no extremo oeste do Estado do Paraná, junto ao rio Paraná, apresentam possibilidade de mistura de águas. Nesta região ocorrem as cotas topográficas mais baixas da Formação Serra Geral.

Poços localizados próximos aos rios: Iguaçu (porção sudoeste do Estado), rio Ivaí (próximo ao contato com o aquífero Caiuá) e três poços situados próximos ao rio Paranapanema, também se caracterizam como regiões com maior probabilidade de mistura de águas entre os sistemas aquíferos Serra Geral e Guarani. 


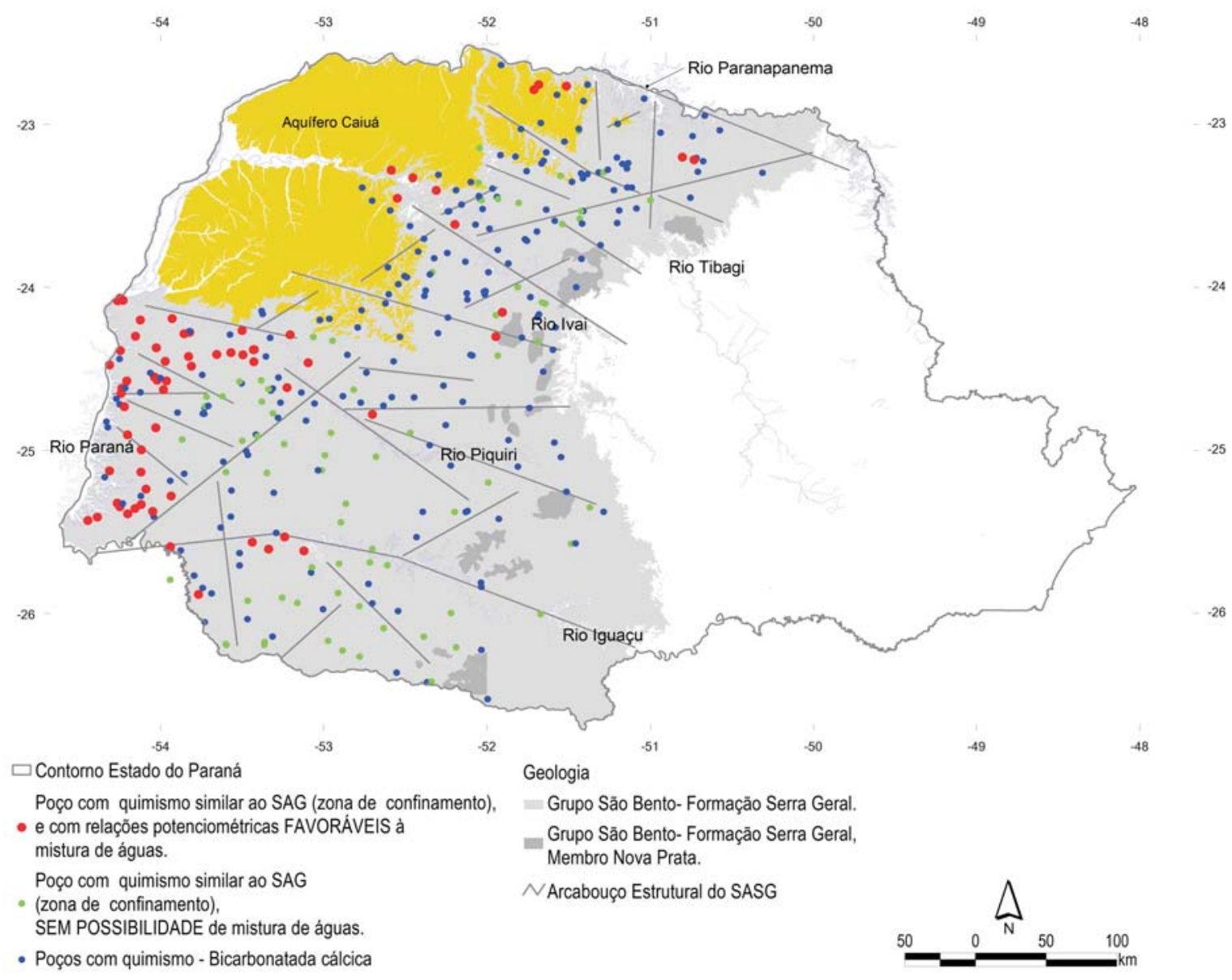

Figura 10 - Localização dos 337 poços do SASG. Em vermelho, poços com indícios de mistura de águas.

\section{CONCLUSÕES}

Na região oeste do Estado do Paraná (próxima ao reservatório de (taipu), grande parte dos poços apresentam condições físicas (potenciométricas) favoráveis para ascensão das águas do SAG até o SASG. Esta região é a área de descarga regional de ambos os aquíferos.

Quando isso ocorre, existe uma "contaminação" do SASG, uma vez que as águas do SAG, nesta região (oeste do PR), apresentam elevadas concentrações de elementos dissolvidos nas águas, com destaque para o sódio, cloreto, sulfato e alto pH. Esta mistura de águas pode inclusive restringir o uso in natura doSASG para consumo humano e irrigação.

Outros possíveis pontos de conectividade e mistura de águas ocorrem próximos ao contato com o
Aquífero Caiuá: um agrupamento de poços localizados na calha do rio Ivaí, e três poços localizados próximos ao rio Paranapanema, no norte do Estado.

É importante ressaltar que deve ser considerada a hipótese de mistura de águas entre o SASG e o SAG apenas quando existe condição potenciométrica favorável. Ainda que a potenciometria seja favorável à mistura de águas, o enriquecimento das águas em sódio, sulfato, elevado $\mathrm{pH}$ e outros, pode ter origem na dissolução dos minerais de preenchimento das fraturas, ou zonalidades geoquímicas dos derrames da Formação Serra Geral. Considerando o exposto, a temperatura é um excelente (e barato) indicador para detectar poços onde ocorrem misturas de águas entre o SAG e SASG. Zonas com concentrações de poços, que apresentem valores anômalos positivos de temperatura, representam locais com maior risco exploratório no SASG. 


\section{Referências bibliográficas}

ATHAYDE G. B. 2013. Compartimentação Hidroestrutural do Sistema Aquífero Serra Geral (SASG) no Estado do Paraná, Brasil. Tese de Doutorado. Pós-Graduação em Geologia. Universidade Federal do Paraná, 155p.

ATHAYDE G., MÜLLER C. V., ROSA FILHO E. F. 2012. Compartimentação Hidroestrutural e aptidões químicas do Sistema Aquífero Serra Geral no estado do Paraná. Revista Brasileira de Geociências, 42 (Suppl 1): 167-185.

ATHAYDE G., MÜLLER C. V, ROSA FILHO E.F., HINDI, E. 2007. Estudo sobre os tipos das águas do Aquífero Serra Geral, no município de Marechal Cândido Rondon-Pr. Águas Subterrâneas, 21: 111-122.

BITTENCOURT A.V.L. 1985. Caracterização geoquímica de águas termais na Bacia do Paraná (Projeto 40.4779/83 - Relatório Técnico), Departamento de Geologia da Universidade Federal do Paraná SURHEMA, 14f. e anexos.

BUCHMANN FILHO A.C. 2002. Características das águas subterrâneas do Sistema Aquífero Serra Geral no Estado do Paraná. Dissertação de Mestrado. PósGraduação em Geologia. Universidade Federal do Paraná, 120p.

BRASIL. 1945. Ministério das Minas e Energia Departamento Nacional da Produção mineral, Decreto-Lei n 7.841 de 08/08/1945 Código de Águas Minerais, Estabelece os princípios de pesquisa, classificação e aproveitamento de águas minerais naturais. Diário Oficial da União, 20/08/1945.

HINDI E.C. 2007. Hidroquímica e hidrotermalismo do Sistema Aquífero Guarani no Estado do Paraná. Tese de Doutorado. Pós-Graduação em Geologia. Universidade Federal do Paraná, 153p.

MINEROPAR. 2006. Minerais do Paraná S.A. Mapa geológico do Estado do Paraná. Escala 1:650.000 Curitiba: Mineropar.

ROSA FILHO E.F; BITTENCOURT A.V.L.; SALAMUNI R. 1987. Contribuição ao estudo das águas subterrâneas nos basaltos no Estado do Paraná. Boletim Paranaense de Geociências, n. 37, p. 22-41.

SOUZA A.A. 2004. Caracterização da bacia do rio Iguaçu, a jusante do município de Reserva do Iguaçu, como área de descarga do aquífero Guarani. Dissertação de Mestrado. Pós-Graduação em Geologia. Universidade Federal do Paraná, 58p. 